\title{
Cohesive Ties in Scientific Texts: An Analytical Approach
}

\author{
Sahar Altikriti ${ }^{1} \&$ Batoul Obaidat ${ }^{2}$ \\ ${ }^{1}$ Department of English, Faculty of Arts, Alzaytoonah University of Jordan, Amman, Jordan \\ ${ }^{2}$ Department of Human Sciences, Faculty of Arts, AL-Zaytoonah Private University, Amman, Jordan \\ Correspondence: Sahar F. Altikriti, Department of English, Faculty of Arts, Alzaytoonah University of Jordan, \\ Amman, Jordan. E-mail: sahar.a@zuj.edu.jo or smallcrystals@yahoo.com
}

Received: March 30, 2017 Accepted: May 5, 2017 Online Published: July 26, 2017

doi:10.5539/ijel.v7n5p127 URL: http://doi.org/10.5539/ijel.v7n5p127

\begin{abstract}
The notion of "textuality" encouraged Halliday and Hasan in 1976 to present their model of discourse analysis through raising questions about whether "cohesion" is a semantic concept or a structural relation, whether a text is a structural unit or not or even if there are semantic or structural relationships within a text. Cohesion is like the glue that unifies the meaning within a text through binding the textual elements. Several studies applied the model of Halliday and Hasan on different texts such as legal, political, narrative, etc., but, very scarce attention has been given to scientific texts. The aim of this study is to examine and analyze some medical texts chosen randomly in terms of the Halliday and Hasan's model by identifying both the lexical and the grammatical cohesive ties. The data analysis shows that the grammatical cohesive ties of reference and the lexical cohesive ties of reiteration carry the highest frequency among other cohesive ties. These results confirmed the significant role of cohesive ties in scientific texts.
\end{abstract}

Keywords: cohesion, cohesive ties, ESP, Halliday and Hasan's taxonomy, medical texts

\section{Introduction}

\subsection{Cohesion: A Review of Literature}

Text Linguistics emerged in the1960s to surmount the limited scope of the sentence-oriented study and brought to the forefront the study from the sentence level to the textual level. Crane (2006) believes that the importance of text with texture is solid for any shortage in this conception would lead to having just a group of sentences where no relationship between them is found. In other words, any text must have the quality of unity, i.e., cohesion. Widdowson (2007, p. 45) states that the term "cohesion" is a linguistic connection that enables to recognize unity in a text such as that between pronouns and the earlier noun phrase. According to Halliday and Hasan (1976, pp. 4, 8-9) "cohesion is not, strictly speaking, a relation above the sentence. In fact, it is a relation to which the sentence or any other form of grammatical structure is simply irrelevant". Therefore, the concept of cohesion is a semantic one which refers to the relations of meaning that exists within the text and that defines it as a text and, so, coherence among elements within the discourse achieved (Beugrande, \& Dressler, 1984; Curse, 2006; Yan, \& Zhou, 2009).

Interestingly, cohesion is sometimes distinguished from coherence since the latter is more concerned with the way a text unified in the mental level: the writer's intention and the reader's comprehension. Thus, to have a better understanding of the important role of coherence in a text, it is necessary to understand the cohesive relations that support any text.

Cohesive ties between sentences stand out as a source of texture, whereas within the sentence there are structural relations. Halliday \& Hasan (1976) distinguished two types of cohesion: grammatical and lexical. For grammatical cohesion, five distinctive categories were classified to indicate the presupposed and presupposing items: "Reference", "Substitution", "Ellipsis", "Lexical Cohesion", and "Conjunction". On the other hand, lexical cohesion is divided into two categories, namely: "Reiteration" and "Collocation" (Zheng, 2002). Although it is expected to find both grammatical and lexical cohesion in a text, but to determine which of them overwhelms the other cannot be predictable.

In this study, the aim of analyzing cohesion in the chosen medical texts is to get answers to the following questions: 
1) Do both grammatical and lexical cohesive ties and their subcategories occur in the medical texts?

2) Are lexical cohesive ties more frequent in use than grammatical ones or vice versa?

3) Is there a relationship between the frequency of certain cohesive ties and the quality of writing medical texts?

4) Are there certain categories used more than others in the medical texts? How are they distributed?

Although, the model of Halliday \& Hasan (1976) is among the first taxonomies proposed for text analysis, yet we believe that it is the most comprehensive and suitable for achieving the purpose of this study. It is expected that this study might lead to the objectives of gaining a better insight of the different usages of the cohesive ties in medical texts.

\section{Cohesive Ties}

As mentioned earlier Halliday \& Hasan (1976) proposed a framework for analyzing cohesive relationships within a text. To analyze a text, cohesive ties are required to give a clear cut account of what constitutes a texture. In other words, recognizing the textual elements that strongly create a unified text such as words, sentence structures and how they might or may not be adjacent to another in a text. Trillo (2008) believes that the presence of cohesive ties in a text would indicate a logical construction. The following subsections give a clear insight

\subsection{Grammatical Cohesive Ties}

These ties are classified into five major ones:

\subsubsection{Reference}

Reference is a semantic relation characterized by the specific nature of the information signaled for retrieval and the cohesion lies in the continuity of reference, whereby the same thing enters into the discourse for the second time (Brown \& Yule, 1983, McCarthy, 2002). Reference items could be either situational (exophoric) or textual (endophoric). The latter can be either anaphoric or cataphoric. This can be shown in the following figure:

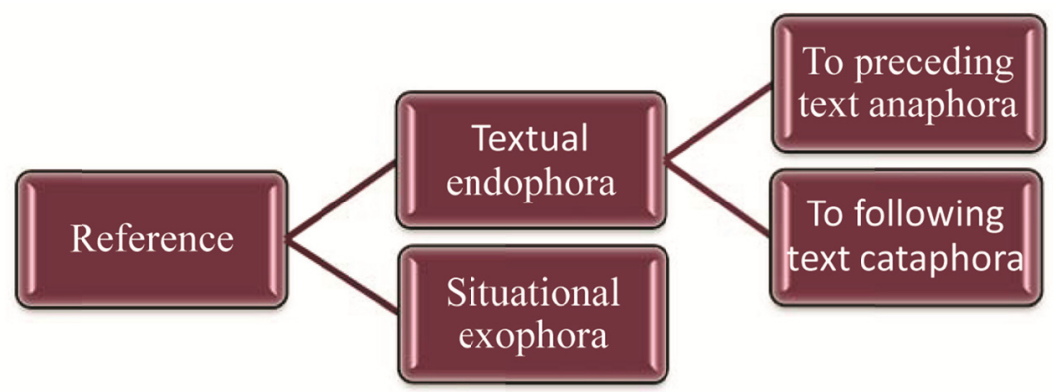

Figure 1. Halliday \& Hasan (1976) classification of reference

The situational reference refers to a thing as identified in the context of the situation, whereas textual reference refers to a thing as identified in the surrounding text (McCarthy, 2002). This was clearly explained in terms of three types of reference: personal reference, demonstrative reference, comparative reference.

\subsubsection{Substitution}

Substitution is a grammatical relation in the wording rather than the meaning. Mathews $(2007$, p. 384) and Halliday \& Hassan (1976, pp. 88-89) describe substitution as the replacement of one item by another. Substitution is a sort of counter, which is used in place of the repetition of a particular item as in "My axe is too blunt. I must get a sharper one" where the word "one" is a substitution of "axe". Thus, it would be entirely possible to replace "one" with "axe", and as a general rule, the substitute item has the same structural function as that for which is substituted. In other words, "one" and 'axe' are both heads in the nominal group. Substitution is classified into three types: nominal, verbal, and clausal.

\subsubsection{Ellipsis}

According to Andrewford (2004, p. 449), ellipsis refers to the process of omission of either a word or part of a sentence in a certain context. On certain occasions, ellipsis are used instead of substitution or as Halliday \& Hasan name it "zero substitution" can be diagnosed when some important structural elements are omitted from a sentence or clause and can only be recovered by referring to an element in the preceding text (Nunan, 1993, p. 25; 
Starkey, 2004, p. 50; Radford, 2004, p. 449). Bloor \& Bloor (1995, p. 96) stated that substitution and ellipsis are cohesive ties used when a speaker or writer wishes to avoid the repetition of a lexical item and is able to draw on one of the grammatical resources of the language to replace the item. Ellipsis can be classified into three types: nominal ellipsis, verbal ellipsis, and clausal ellipsis.

\subsubsection{Conjunction}

The nature of the conjunction is rather different from the other cohesive relations and it is not simply an anaphoric relation. The conjunctive elements are indirectly cohesive due to their definite meanings. In other words, they are not used for reaching the previous or the following elements in the text, but they rather express and presuppose the meaning and the occurrence of other elements in the text. Halliday \& Hassan (1976, p. 227) pointed out that in describing conjunction as a cohesive device, attention is focused not on the semantic relations as such, as realized throughout the grammar of the language, but on particular aspects of them, namely the function they have of relating to each other linguistic elements that occur in succession but are not related by other, structural means. The conjunctive relations are not logical, but textual, i.e., they represent the generalized types of connection that we recognize as holding between sentences (Crystal, 2003; Farrokhpey, 1999). The conjunction relations are classified into four basic types: additive, casual, adversative, and temporal.

\subsection{Lexical Cohesive Ties}

These ties are classified into "reiteration" and "collocation":

\subsubsection{Reiteration}

Reiteration is one of the types of lexical cohesion which entails the repetition of a lexical item at one end of the scale, the use of a general word to refer back to a lexical item, at the other end of a scale, and a number of things in between the use of synonym or near-synonym. Also, a reiterated item may be a repetition or a general word; and in most cases, it is accompanied by a reference item typically "the" as in "I turned to the ascent of the peak" (Andrewford, 2004, p. 349).

\subsubsection{Collocation}

It refers to any two lexical item having similar patterns of collection and their occurrence in adjacent sentences will generate a cohesive force. Mathews, (2007, p. 93) explains that this effect is not limited to a pair of words, but it is very common for long cohesive chains to be built up out of lexical relations of this kind with word patterns like a candle, flame, flicker, hair, comb, curl, etc. such patterns occur freely both within the same sentence and across sentence boundaries.

\section{English for Specific Purposes (ESP)}

The notion of English for Specific Purposes (ESP) started in the early 1960s as a result of an international movement in the domain of English language teaching. The purpose of this field is to help international students with developing their skills of writing and also to assist researchers in non-English speaking countries to publish their works in English. The sphere of ESP covers English for waiters, Business English, Scientific English, English for medical professionals, English for tourism, etc. (Johns \& Dudly-Evans, 1991; Belcher, 2009; Johns, 2013).

Originally speaking, ESP lies heavily in the field of linguistics where ESP researchers turned their attention from the sentence level to the discourse level and become more concerned with the "rhetorical functions". According to Trimble (1985), such functions may be realized differently in specific purpose texts like those definitions, classification, description, narration, generalizations, etc. In an advanced level of research, the linguists found that linguistic features and discourse structures can be looked at from within the context of genres or even specific texts.

Text genre is a term originated in literary studies and then developed to be widely used in other disciplines such as those of knowledge. Several scholars adopted the term and related it to linguistics, such as Halliday \& Hasan (1985), Swales (1990), Martin (1992) and many others. Therefore, the language for specific purposes can be considered as a genre in accordance with its text types or subgenres. One of these text types is the scientific writing type (more specifically the medical text type) which is the concern of the present study to analyze.

\subsection{Scientific Genre: Medical Writing}

Scientific writing differs from other genres of writing in that scientific language is characterized as formal, informative, consistent, straightforward, concise, comprehensible and brief (Ahmad, 2012). A scientist message would be misunderstood if he / she uses complicated or ambiguous sentences, thus the language of scientific writing should not be complex, as Day $(1979$, p. 5) states: 
In scientific writing, language need not be difficult; and the best English is that which gives the senses in the fewest short words. Literary tricks, metaphors and the like, divert attention from the message to the style. They should be used rarely, if at all, in scientific writing.

Medical texts are one of the scientific text types which are written either by and for physicians or for the public. The language of such medical texts differs in accordance with the type of the addressee, and hence, the linguistic and textual features of these texts differ. What characterizes written texts is the absence of the immediate interaction with readers and it is for this reason authors intend to use a collection of lexical, grammatical and structural devices to identify the relations between text elements to convey the intended message. Therefore, the selected data in the present study will be analyzed in terms of those aspects.

\section{Method and Data Analysis}

On the basis of Halliday \& Hasan (1976) framework, the present study aims to identify and analyze cohesive ties found in some medical texts taken randomly from the sources (For full information see the References):

(1) Harper, N., The Journal of Prevention, diagnosis, and treatment

(2) Houghton, A., An Introduction to Medical Diagnosis.

(3) Smith, C. S., Medicine International.

As mentioned earlier, the aim of the present study is to provide an answer to whether both grammatical and lexical cohesive ties occur in the selected data or not. In addition, the data analysis is made to seek answers of which cohesive ties carried the highest frequency and which subcategories are used more than others.

\section{Results}

The analysis of the five medical texts revealed that both grammatical and lexical cohesive ties are used. Although both types have an approximate occurrence in the data, yet their subcategories vary as shown in Table (1). The highest frequency goes to "reference" as a type of grammatical cohesive ties making up (33\%) out of the total cohesive ties (123) in the selected data. On the other hand, "reiteration" represents the highest frequency as a type of lexical cohesive ties representing $(42 \%)$ out of the total. Therefore, the data analysis shows a significant difference between the types of cohesive ties in the selected medical texts.

Table 1. The cohesive ties in the selected data

\begin{tabular}{llll}
\hline Cohesive Ties & Sub-ties & Frequency & Percentage \\
\hline \multirow{2}{*}{ Grammatical } & Reference & 41 & $33 \%$ \\
& Substitution & 0 & 0 \\
& Ellipsis & 5 & $4 \%$ \\
& Conjunction & 16 & $13 \%$ \\
\hline Lexical & Reiteration & 51 & $42 \%$ \\
& Collocation & 10 & $8 \%$ \\
\hline Total & & $\mathbf{1 2 3}$ & $\mathbf{1 0 0 \%}$ \\
\hline
\end{tabular}

\subsection{Grammatical Cohesion}

\subsubsection{Reference}

In the present study, the analysis of the five selected texts reveals the excessive usage of "reference" as a type of cohesive ties with (41) instances making up (66\%) of the total grammatical cohesive ties (62). Among the three types of reference recognized in the data were those of demonstratives with (31) instances, whereas personal or comparative references identified in (6) and (4) instances respectively as shown in (Graph 1). Demonstratives refer to their referents by specifying their location on a scale of proximity and this is how "this" in the example (1) is realized. It is anaphoric as it refers back to the word "Ulcer":

(1) Ulcer. This may occur in the body of the stomach or on either side

On the other hand, demonstratives can be categorized such as "the" in the example (2) below:

(2) The dip in the curve was chosen as the boundary between normal and high blood pressure.

The demonstrative "the" refers forward to the modifying element within the nominal group itself. It identifies the line that separates between normal and high blood pressure and therefore its meaning is recoverable from the text. 
On the level of personal reference, a reference is recognized by means of function in the speech situation through the category of person. In example (3), the personal reference "it" can be realized as either anaphoric or cataphoric and sometimes both:

(3) Diabetes mellitus, a regulatory and metabolic disease, is caused by insufficient pancreatic function. It affects and ever increasing number of individuals, and the incidence of diabetic complication.

In this example, the personal pronoun "it" refers back to a previous lexical item "Diabetes mellitus" mentioned in the first sentence, therefore, it is anaphoric. At the same time, it is cataphoric since it refers to the way diabetes mellitus affects an increasing number of individuals.

In the case of "comparative reference", only (4) instances occurred in the data (as mentioned above), the following is an example:

(4) Gastritis with hyperchlorhydria may exist without symptoms unless an ulcer is also present, but in some cases symptoms similar to those of ulcer apparently occur.

The comparative reference 'similar to' is cataphoric referring to the similarity between the symptoms of gastritis and those of ulcer.

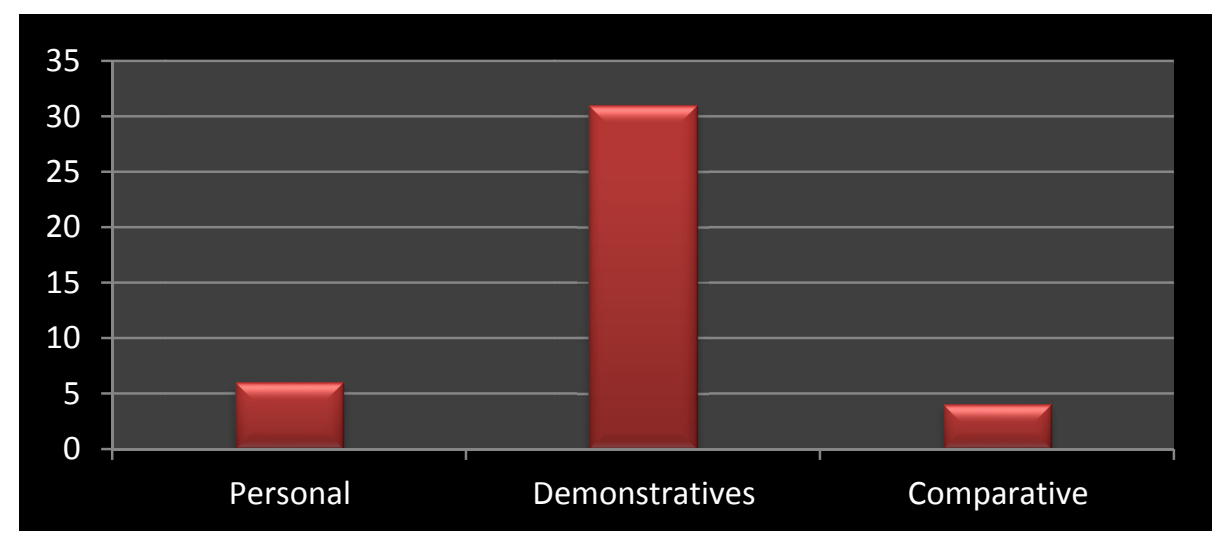

Graph 1. Frequencies of reference cohesive ties in medical texts

\subsubsection{Ellipsis}

Very few cases of ellipsis were recognized in the data and found in only (5) instances with (8\%) out of the total cohesive ties in the data. The analysis has shown that the clausal ellipsis carried the highest frequency realized in (4) instances whereas verbal ellipsis is used only once. Interestingly, the analysis also revealed that there are no incidents of nominal ellipsis (See Graph 2). In the following example, the subject, "they", of the clause is being elliptic before the verb "avoided":

(5) Observers were anxious to place subjects in one or other category and unconsciously avoided the boundary zone.

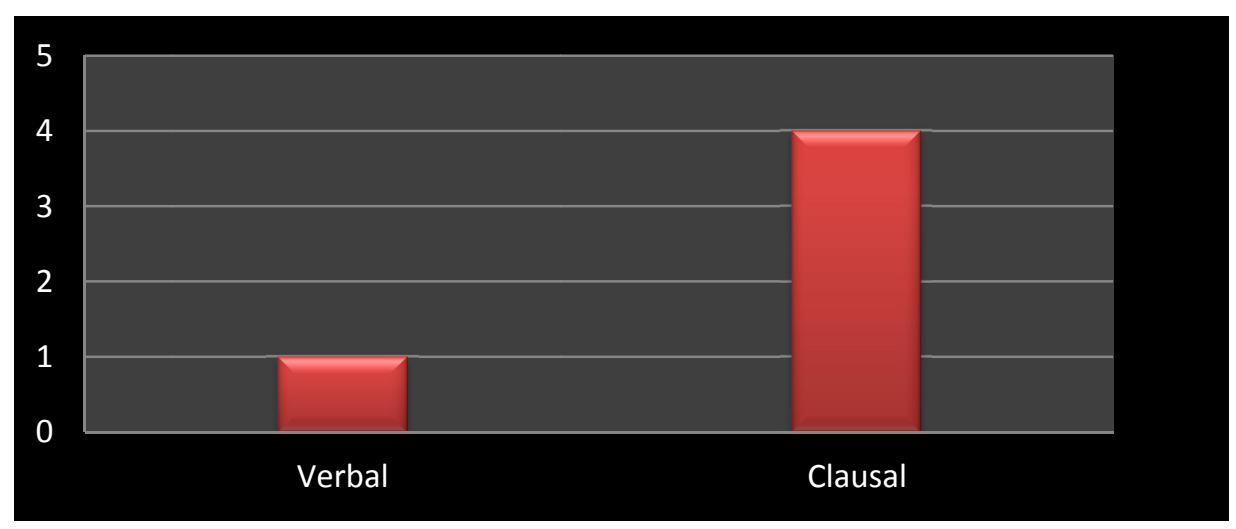

Graph 2. Frequencies of ellipsis cohesive ties in medical texts 


\subsubsection{Conjunction}

The data analysis has interestingly shown that conjunction cohesive ties represent the second highest frequency next to those of "reference" making up (16\%) out of the total grammatical cohesive ties (62). Among its types, temporal specification and adversatives are the most frequently used cohesive ties identified in (6) and (5) instances respectively; whereas the least incidents are realized by both additive and causal cohesive ties. In the example (6) below, the temporal conjunct "often" is an indicator of the consistent relation between certain symptoms and the patients suffer from the endocrine disorder in the long term.

(6) Certain symptoms should, and often do, suggest to the general practitioner that his patient is suffering from an endocrine disorder.

Additive and causal conjuncts are also recognized in the selected data, although with very few instances as shown in Graph 3). In example (7), the conjunct "furthermore" conveyed the addition of new information in relation to a previous one in the text, whereas in the example (8), the casual conjunction "because of" is reflected as an emphatic conjunction emphasizing on the reason that makes maturity-onset diabetes uncommon.

(7) Furthermore, such factors us unbalanced diets and insufficient physical exercise may contribute to the increase in the number of patients suffering from diabetes mellitus.

(8) And maturity-onset diabetes was uncommon because of the limited life expectancy.

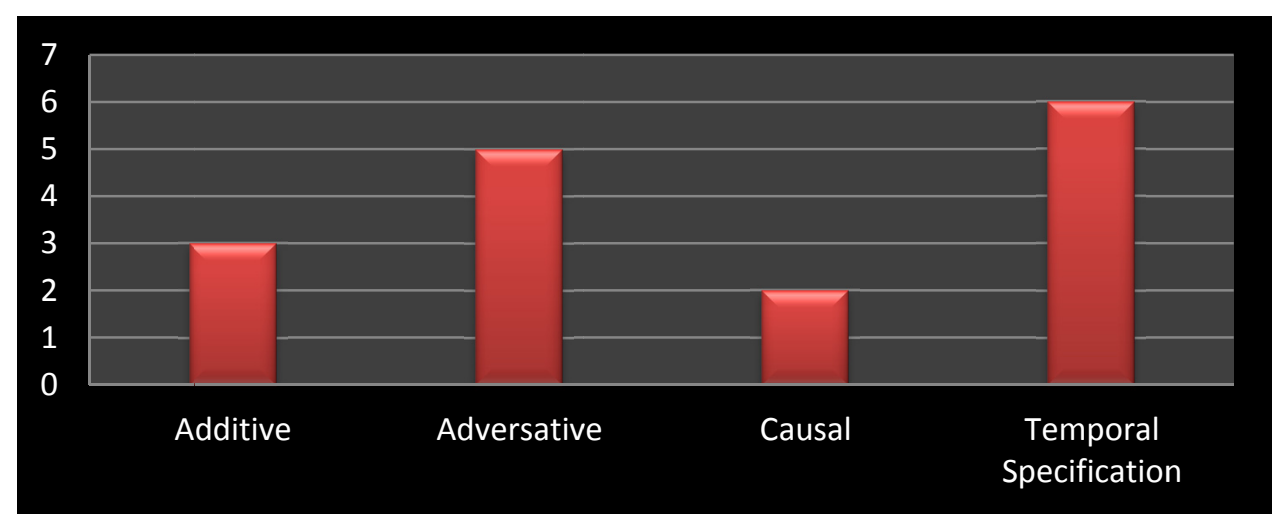

Graph 3. Frequencies of conjunction cohesive ties in medical texts

\subsection{Lexical Relations}

Lexical relations signify the second level of data analysis in the present study. The analysis revealed that the lexical cohesive ties of "reiteration" overwhelm those of "collocation" representing (51) making up (84\%) while only (10) instances of collocation occur in the data accounting (16\%) out of the total lexical cohesive ties (61). (See Graph 4).

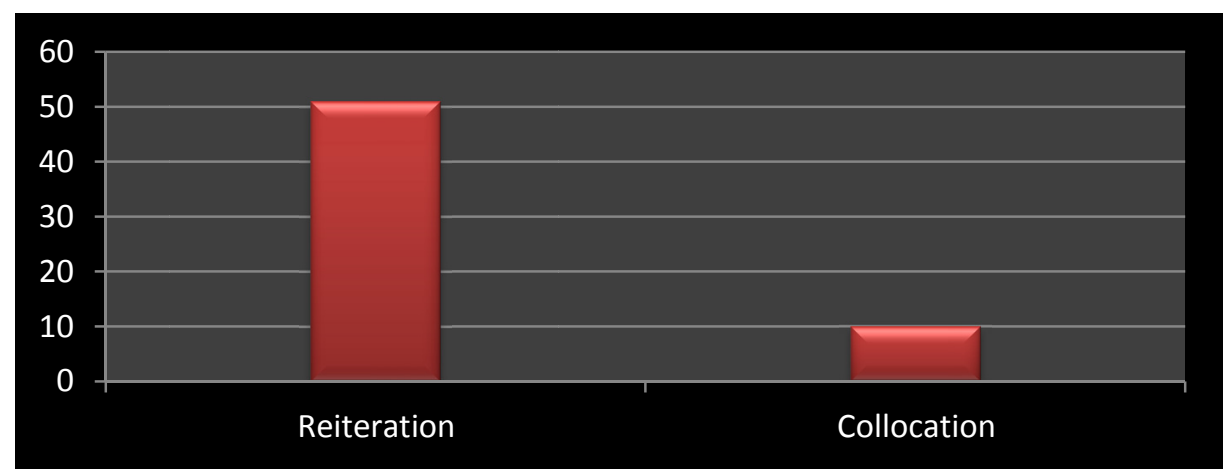

Graph 4. Frequencies of lexical relations in the data 
The word "chronic" is an example of the cohesive ties of reiteration as it appears in four instances within one text. This repetitive case is a clear indication of cohesion.

(9) In a chronic form, gastritis occurs as a chronic catarrhal inflammation. (10) .which cause a chronic gastritis.

(11) Chronic suppuration or infection of the nasal sinuses

On the other hand, cases of collocation also occurred, though with less incidences such as "duodenal" collocating with "gastritis" and "ulcer".

\section{Conclusions}

The present study aimed at examining and investigating the use of cohesive ties, their application and discursive function in the genre of medical texts. Herein, the analysis of the data provided answers to the research questions in the following findings:

1) Both grammatical and lexical cohesive ties are employed in medical texts. Their usage played an important role in making medical texts coherent, direct, objective and explicit.

2) The grammatical cohesion was found to be slightly higher in terms of frequency of occurrence than those of lexical cohesion; albeit the highest frequency is represented by the lexical cohesive ties of "reiteration" signaling a significant and contributing feature to the cohesion and unity of medical texts. On the other hand, few instances of collocation were presented in the data. This is due to the fact that from a communicative perspective, certain lexical items are repeated to emphasize the medical content. Hence, since medical texts are of an informative orientation, lexical cohesion plays a crucial role in constructing a coherent text.

3) On the grammatical level, the highest frequency goes to the cohesive ties of "reference" which provides a sense of identifiability in the medical texts. Among the reference cohesive ties, "demonstratives" held the highest frequency, whereas personal and comparative cohesive ties carried the lowest frequency. The analysis also revealed that reference cohesive ties were endophoric.

4) The cohesive ties of "ellipsis", "conjunction" and "temporal specification" and surprisingly the data analysis identified zero occurrences of substitution. This is a clear indication that medical texts are written to be concise and firm in its structure which would deliver clear cut information without ambiguity.

As a conclusion, it can be said that although there were different studies concerning cohesion and cohesive ties, the present study is based on Halliday and Hasan's model (1976) in the analysis of some medical texts. The results of the analysis met the proposed purpose of this study in determining the pivotal role of both lexical and grammatical cohesive ties in unifying and structuring any text, especially medical texts. Therefore, the findings of this study may help researchers have a better understanding of the use and function of cohesive ties in scientific texts and pave the way for other cases of analysis in relation to other discourse examination.

\section{Recommendations for Further Research}

The researcher suggests the following ideas for further research:

1) Examining and investigating cohesive ties in English medical brochures with their Arabic translation.

2) Investigating either lexical or grammatical cohesive ties in other genres.

\section{References}

Ahmad, J. (2012). Stylistic Features of Scientific English: A Study of Scientific Research Articles. English Language and Literature Studies, 2. https://doi.org/10.5539/ells.v2n1p47

Andrewford, T. (2004). Text and Discourse Analysis. London: T. J. International Ltd, Pad stow, Cornwall.

Belcher, D. (2009). What ESP is and can be: An introduction. In D. Belcher (Ed.), English for specific purposes in theory and practice (pp. 1-20). Ann Arbor: University of Michigan Press. https://doi.org/10.3998/mpub.770237

Beugrande, R., \& Dressler, W. (1984). Introduction to text linguistics. London: Longman.

Bloor, T., \& Bloor, M. (1995). The Functional Analysis of English. London: Arnold.

Brown, G., \& Yule, G. (1983). Discourse Analysis. Cambridge: Cambridge University Press. https://doi.org/10.1017/CBO9780511805226

Crane, P. A. (2006). Texture in Text: A Discourse Analysis of a News Article Using Halliday and Hasan's Model of Cohesion. Journal of School of Foreign Languages, 30, 131-156. 
Crystal, D. (2003). Cambridge Encyclopedia of Language. London: Longman.

Day, R. A. (1979). How to Write and Publish a Scientific Paper. Philadelphia: ISI Press.

Farrokhpey, M. (1999). Fundamental Concepts in Linguistics. Tehran: Sokhan.

Halliday, M., \& Hasan. (1976), Cohesion in English. London: Longman group Ltd. https://doi.org/10.4324/9781315836010

Halliday, M., \& Hasan. (1985). An Introduction to Functional Grammar. London: Edward Arnold.

Harper, N. (1985). Distribution of Blood Pressure' in Postgraduate Doctor. The Journal of Prevention, Diagnosis and Treatment, 8(3).

Houghton, A. R., \& Gray, D. (2010). Chamberlain's Symptoms and Signs in Clinical Medicine 13th Edition, An Introduction to Medical Diagnosis. Great Britain: Taylor \& Francis Ltd.

Johns, A. M. (2013). The history of English for specific research purposes. In B. Partridge \& S. Starfield (Eds.), The handbook of English for specific purposes. Boston: Wiley-Blackwell.

Johns, A. M., \& Dudley-Evans, T. (1991), English for Specific Purposes: International in Scope, Specific in Purpose. TESOL Quarterly, 25(2), 297-314. https://doi.org/10.2307/3587465

Martin, JR. (1992). English Text: systems and structure. Amsterdam: John Benjamins. https://doi.org/10.1075/z.59

Matthews, P. H. (2007). Oxford Concise Dictionary of Linguistics. Oxford: Oxford University Press.

McCarthy, M. (1991). Discourse Analysis for Language Teacher. Cambridge: Cambridge University Press.

Nunan, D. (1993). Task-based syllabus design: Selecting, grading and sequencing tasks. In G. Crooks \& S. Gass (Eds.).

Redford, S. (2004). Concept of Cohesion. London: Longman.

Smith, C. S. (1983). Medicine International, 1(36). London: Medical Education Ltd.

Starkey, M. (2004). Cohesion in English. London: Longman.

Swales, J. (1990). Genre analysis. English in academic and research settings. Cambridge: Cambridge University Press. https://doi.org/10.1075/z.184.513swa

Trillo, J. R. (2008). Discourse markers/ pragmatic markers. SCI Topics. Retrieved from http://www.scitopics.com/Discourse_Markers_Pragmatic_Markers.html

Trimble, L. (1985). English for science and technology: a discourse approach. Cambridge: Cambridge University Press. https://doi.org/10.1016/0346-251x(88)90040-1

Widdowson, H. G. (2007). Discourse analysis. Oxford: Oxford.

Zhao, J., Yan, W., \& Zhou, Y. (2009). A Corpus-Based Study of Cohesion in English Medical Texts and its Chinese Translation. Retrieved from https://www.ncbi.nlm.nih.gov/pmc/articles

Zheng, G. Y. (2002). Chinese Textual Linguistics. Beijing: Foreign Languages Press.

\section{Copyrights}

Copyright for this article is retained by the author(s), with first publication rights granted to the journal.

This is an open-access article distributed under the terms and conditions of the Creative Commons Attribution license (http://creativecommons.org/licenses/by/4.0/). 